\title{
USO E OCUPAÇÃO DO SOLO URBANO: UMA ANÁLISE DOS IMPACTOS AMBIENTAIS NAS ÁREAS DE DUNAS NO BAIRRO DE FELIPE CAMARÃO/NATAL-RN
}

\author{
P. J. SILVA \\ Universidade Federal do Rio Grande do Norte - UFRN \\ paulajuliana1@gmail.com
}

Artigo submetido em agosto/2014 e aceito em junho/2015

DOI: $10.15628 /$ holos.2015.2350

\section{RESUMO}

Este trabalho visa analisar os principais impactos ambientais gerados pelo uso e ocupação das áreas de dunas na zona administrativa Oeste da cidade, destacando o bairro de Felipe Camarão, o que se torna uma questão de interesse, principalmente, para a população e para o gestor público municipal. A degradação da área ocorre na medida em que o uso do solo, sem o devido planejamento, acelera os processos de dinâmica natural e estes, por sua vez, passam a serem agentes causadores, muitas vezes, de riscos naturais para a própria população. Diante disso, pode-se perceber que as áreas de dunas no bairro vêm sofrendo constantemente pelo uso determinados de varias ações, tais como: construção de casas; retirada de vegetação para abertura de vias; depósito de resíduos sólidos; retirada de área para a construção e outros. Isso, consequentemente, tem provocados alguns impactos ambientais, como: cortes e aterros de grandes extensões causando compactação e erosão do solo. A metodologia utilizada se pautou em um levantamento bibliográfico, visitas in loco sendo acompanhada de registros fotográficos, além de entrevistas informais aos diversos agentes sociais envolvidos.

PALAVRAS-CHAVE: Solo urbano, dunas, impactos ambientais e urbanização.

\section{USE AND OCCUPANCY OF URBAN LAND: AN ANALYSIS OF ENVIRONMENTAL IMPACTS IN THE AREAS OF DUNES IN THE NEIGHBORHOOD OF FELIPE CAMARÃO/NATAL-RN}

\begin{abstract}
This work aims to analyze the main environmental impacts generated by the use and occupancy of dune areas in the administrative west area of the city, highlighting the neighborhood Felipe Camarão, which becomes a matter of interest, especially for the population and for the municipal public manager. The degradation in the area occurs as the land use, without the proper planning, speeds up the natural dynamic processes and these, on the other hand, became often the causative agents of natural hazards for the people themselves. Thus, it can be seen that the dune areas in
\end{abstract}

the neighborhood are suffering constantly determined by the use of various actions, such as: building houses, removal of vegetation to open roads, solid waste disposal, removal area for construction and others. This consequently has caused some environmental impacts, such as cuts and embankments of large areas causing soil erosion and compaction. The methodology is guided in a bibliographic research, site visits accompanied by photographic records, and informal interviews with various social actors involved.

KEYWORDS: Urban soil, dunes, environmental impacts and urbanization. 


\section{INTRODUÇÃO}

O crescimento urbano desordenado e desigual nas cidades brasileiras tem acarretado, em muitos casos, uma série de problemas que implicam no desenvolvimento funcional e no uso e ocupação do espaço. Segundo o censo de 1940, promovido pelo Instituto Brasileiro de Geografia e Estatísticas (IBGE), no qual a população brasileira foi dividida pela primeira vez em rural e urbana, apenas 29,31\% da população vivia em zonas urbanas. Na década de 1970, mais da metade da população já vivia em zonas urbanas, o que, de acordo com o IBGE, atingia 55,92\% da população total. Na década de $1980,67,59 \%$ da população vivia em zona urbana. No ano de 1996, 78,35\% dos brasileiros residiam nas áreas urbanas. Esse número subiu para $81,24 \%$ em 2000 , e, no último censo, constatou-se $84,36 \%$ da população vivendo na zona urbana. Esse panorama de crescimento da população brasileira demonstra que houve uma inversão na distribuição da população em curto espaço de tempo.

As cidades brasileiras não estavam preparadas para um crescimento populacional tão rápido, por isso, acumularam, a partir de então, problemas de todas as ordens, tornando cada vez mais desigual a distribuição dos recursos, principalmente para as áreas de infraestruturas, equipamentos e serviços nas áreas urbanas. A concentração dos investimentos públicos ocorreu nas áreas onde se concentravam os mais ricos, perpetuando as dificuldades das ocupações nas áreas periféricas. Ao mesmo tempo, como explica Santos (1990, p.25), quando a cidade expande seus limites, deixa, em seu interior, grande quantidade de terrenos vazios.

Em Natal, não foi diferente. O processo de crescimento urbano, motivado pela participação na Segunda Guerra Mundial, na década de 1940, fez com que áreas de difícil acesso e até mesmo "naturais", servissem e sirvam de locus para (re)produção do espaço, tais como: leitos de rios, manguezais, regiões de dunas e outros. Em vista disso, compreende-se que a infraestrutura básica de serviços e equipamentos em Natal não tem sido suficiente e adequada para comportar com qualidade ambiental o grande número da população e, consequentemente, o número de residências. Assim, parte da população, principalmente as de menor poder aquisitivo, tem ocupado áreas de risco, como no caso dos morros.

Nesse contexto, este trabalho visa analisar os principais impactos ambientais gerados pelo uso e ocupação das áreas de dunas na Zona Oeste da cidade do Natal, destacando o bairro de Felipe Camarão, os quais se tornam questões de interesses, principalmente, para a população e para o gestor público municipal. A degradação das dunas ocorre na medida em que o uso do solo, sem o devido planejamento, acelera os processos de dinâmica natural e estes, por sua vez, passam a serem agentes causadores de riscos naturais para a própria população. Deve-se ensejar que o processo de urbanização seja estrategicamente planejado e que os problemas oriundos da relação homem - ambiente seja mitigados para garantir uma boa qualidade de vida para os que usufruem.

\section{USO E OCUPAÇÃO DO SOLO URBANO DE NATAL}

É difícil descrever o uso e ocupação do solo urbano sem falar do principal agente transformador do espaço geográfico - o homem. Como descreve Araújo (2007): 
As sociedades humanas, ao produzirem sua vida material e sua história, modificam os ambientes naturais e produzem também espaço. $O$ processo de humanização da natureza e de transformação desta em recurso produtivo resulta na produção do espaço geográfico (ARAúJO, 2007, p.9).

A apropriação da sociedade sobre o meio ambiente em busca de recursos para serem utilizados em seus benefícios transforma esse meio natural em uma paisagem construída, negligenciando, na maioria dos casos, os ambientes naturais frágeis. De acordo com Victoriano (2000, p.19), ele denomina essa apropriação de "desarmonia", ou seja, a desarmonia entre o homem e o meio é causada pela falta de valores sociais.

Na cidade do Natal a escolha de uso e ocupação do solo urbano dar-se-á de forma diferenciada. Em alguns lugares, principalmente, onde há uma boa infraestrutura de equipamentos urbanos, o capital tenderá a ser mais abundante, caso contrário, o investimento ocorrerá em menor proporção. Esses investimentos têm ocorrido com frequência, principalmente, nas áreas onde a atividade turística é mais acentuada, ou seja, na zona administrativa Sul e Leste da cidade. São nesses locais que estão concentrados os maiores fluxos de turistas estrangeiros e a maior renda per capita da cidade; as pessoas que residem nessas áreas ganham, em média, onze salários mínimos (NATAL, 2009).

Ainda nessas áreas supracitadas estão localizados empreendimentos de grande expressividade que atendem a demanda do modo de produção capitalista, tais como: supermercados, hipermercados, agências bancárias, universidades públicas e privadas, postos de combustíveis, hotéis, bares, restaurantes, e, com destaque, os shopping-centers (NASCIMENTO, 2003). Com isso, essas áreas tornam-se cada vez mais valorizadas e os agentes produtores do espaço, em parceria com o poder público, voltam-se, totalmente, seus olhares para lá.

Todo esse investimento faz com que o solo urbano adquira certo valor, e torne-se, então, uma mercadoria, sendo disputada, somente, por aqueles agentes que podem pagar para adquirila. Podemos, então, acrescentar que a ação desses agentes tem ocorrido de forma fragmentada e articulada no espaço (CORRÊA, 1995). A fragmentação ocorre pelas formas de uso que cada agente faz do espaço, através das relações sociais, econômicas ou mesmo na aquisição de moradias. Essa fragmentação tem sido decorrente das ações dos diversos agentes que modelam e produzem o espaço urbano. A articulação se dá de forma simultânea, uma vez que cada uma das partes da cidade mantém relações com as demais. De acordo com Corrêa (2001), essa articulação não está atrelada somente ao modo empírico: aos fluxos de veículos e de pessoas, mas também ao modo menos visível: através das relações capitalistas que envolvem a circulação de decisões e investimentos de capital, mais-valia, salários, juros, rendas e outros. Tudo isso faz com que até mesmo as áreas de dunas na cidade, que devem ser preservadas e ter um planejamento adequado de uso, ganhem notoriedade aumentando a especulação do solo urbano e, consequentemente, provocando a remodelação do espaço com a retirada de sedimentos, desmatamentos, queimadas, aterramentos e abertura de trilhas em locais impróprios, entre outros.

Por outro lado, a distribuição espacial de infraestruturas urbanas na cidade não ocorre de maneira justa; o foco está voltado para os interesses privados, incluindo os do mercado imobiliário. Com isso, a saída encontrada pelas classes de menor poder aquisitivo para habitar a cidade é o comércio informal e ilegal de terras. Este comércio, segundo Abramo (2007), está 
atribuído a vários fatores, mas, sobretudo, a uma legislação urbanística modernista, que dialoga com os estratos de renda elevados. O modelo de cidade formal modernista impõe um conjunto de requisitos normativos, que produziu uma verdadeira barreira institucional para a provisão de moradias para os setores populares com rendimento abaixo de três salários mínimos, e induziu a ação irregular e/ou clandestina de loteadores e processos de ocupação popular de glebas urbanas e periurbanas.

No Brasil, a informalidade da terra não está relacionada somente aos mais pobres, mas também a outros grupos sociais mais privilegiados. São muitas as formas de violação da ordem jurídica também entre as classes médias e altas, e a ênfase maior dada aos assentamentos informais decorre da maior urgência de enfrentamento desse processo. Além disso, as taxas de crescimento da informalidade urbana têm sido maiores do que as taxas de crescimento da pobreza (FERNANDES, 2006).

O papel do Estado, nesta situação, deve ser de intervir regulando os mercados imobiliários de tal forma que promova políticas de subsídios que atendam determinados fatores, apontados por Valença (2003), como:

[...] reduzir os custos de produção como também do acesso à moradia; desenvolvendo políticas de controle e concessão de crédito para viabilizar a atividade imobiliária (capital de giro) e o consumo (demanda/financiamento a longo prazo); desenvolvendo políticas de investimento público no setor para favorecimento dos mais pobres; promovendo o desenvolvimento tecnológico do setor de construção civil e produção de materiais; procurando exercer controle sobre o preço da terra, resgatando parcial ou totalmente a renda da terra, produto do trabalho social, apropriada pelo proprietário(e para isso podem ser utilizados os impostos sobre o terreno e a edificação, sobre a renda, etc.); promovendo o emprego e a renda, incrementando o poder de compra (VALENÇA, 2003, p.169-170).

O que se observa é o contrário. A maioria das obras desenvolvidas pela gestão urbana (municipal e estadual) não democratiza o acesso à terra urbana; pelo contrário, fortalece e alimenta ainda mais a especulação ao direcionar investimentos públicos que valorizam propriedades fundiárias ou imobiliárias, especialmente por meio da abertura de circulação viária. A lógica não está em melhorar os serviços de transportes, mas a dinâmica de abrir novas frentes (localizações) para o mercado imobiliário de alta renda (MARICATO, 2000). Por outro lado, há também uma falta de eficácia nos programas de regularização das terras urbanas, observada por Fernandes (2006):

Tais programas não têm intervindo de maneira significativa na estrutura fundiária, especialmente por terem pouca relação com outras políticas públicas acerca dos vazios urbanos, imóveis subutilizados e terras públicas. De modo geral, os programas de regularização não têm sido devidamente compatibilizados com o quadro mais amplo de políticas públicas fundiárias, urbanas, habitacionais, fiscais e orçamentárias, e têm falhado ao não reverter a tradição de concentração desigual de equipamentos e serviços públicos. Como tal, tais políticas e programas não têm conseguido quebrar o círculo vicioso que há tempos tem produzido os processos de desenvolvimento urbano informal. Também de maneira geral, tais programas não têm traduzido seus objetivos declarados com os processos sociopolíticos, mecanismos institucionais, recursos 
financeiros e instrumentos jurídicos urbanísticos que são necessários. Com freqüência, os programas de regularização têm sido objeto de manipulação política por partidos e políticos de diversas tendências (FERNANDES, 2006, p. 52).

O comércio informal e a ocupação ilegal da terra são tolerados pelo Estado quando não interferem no circuito central da realização de lucro do setor imobiliário. Mas, caso venha a interferir, o Estado entra como o principal mediador deste conflito, alimentando ainda mais o processo restritivo, especulativo, excludente, discriminatório do sistema capitalista sobre o fundiário.

Ao instituir uma legislação de parcelamento do solo urbano, o Estado se torna um importante indutor da produção do espaço urbano. É ele quem define as áreas que podem ser ocupadas para cada finalidade específica, por meio da legislação. Como exemplo, podemos citar as Zonas de Proteção Ambiental, entre outras, que são delimitadas por uso e ocupação restritos, mediante a lei. Dessa forma, ao definir as formas de uso e ocupação, a lei interfere diretamente no valor do solo, e a legislação não é desprovida de intencionalidades, ao contrário, verifica-se, na maioria das vezes, que ela beneficia os interesses capitalistas, mistificando a função social da propriedade.

Em relação ao objeto de estudo desta pesquisa, observou-se que boa parte das áreas de dunas que constituem a área urbana da zona administrativa Oeste, especificamente, o bairro de Felipe Camarão vem sendo ocupada e usada de forma irregular, principalmente se tratando da sustentabilidade ambiental, por uma parcela da população menos abastada. As áreas de dunas estão praticamente sendo invadidas pela população, muitos lotearam algumas partes para comercializar, foram abertas vias de acesso para o outro lado da duna; além da retira excessiva da areia para algum tipo de construção e reparos nas casas, ou servem como um local para depósito de lixo.

Diante dessa realidade, percebe-se que os moradores que usam e ocupam as dunas não tem o conhecimento do risco que está correndo por aquele espaço ser uma área de solo frágil e também por ser uma área importante que precisa ser preservada. Nas conversas informais com alguns moradores, muitos reclamaram da dificuldade da coleta de lixo chegar até lá e do perigo de circular em determina hora do dia.

\section{PROCEDIMENTOS METODOLÓGICOS}

Para analisar os impactos ambientais decorrentes do uso e ocupação do solo nas áreas de dunas do bairro de Felipe Camarão, privilegiou tanto uma pesquisa bibliográfica e documental, quanto uma pesquisa empírica. A operacionalização deste estudo consistirá em duas etapas.

\subsection{1a Etapa: Obtenção de dados (Levantamento bibliográfico e documental)}

Esta fase da pesquisa foi realizada de forma contínua, com o objetivo de nos dotar de uma base teórico-conceitual no âmbito de publicações existentes acerca ou relacionados com o presente estudo em escala local e nacional, que foram imprescindíveis nas análises requeridas.

Em vista disso, realizou-se um levantamento bibliográfico junto ao acervo bibliográfico da Biblioteca Central da Universidade Federal do Rio Grande do Norte, assim como, nas bibliotecas 
setoriais dos departamentos de Geografia, meio ambiente, história e Arquitetura e Urbanismo. Foram feitas pesquisas em sites oficiais como o portal da capes, que contêm dissertações e teses, o site da revista de Geografia e Ciências Sociais, Scripta Nova, que abriga artigos diversos, e o site do Ministério do Meio Ambiente e o site da Secretaria Municipal de Meio Ambiente e Urbanismo da cidade de Natal (SEMURB). Ainda foi realizado um levantamento de informações relacionadas aos eventos que configuraram a atual situação ambiental em questão, em jornais e revistas de circulação local. Para a produção de informações sobre a realidade ambiental do uso e ocupação antrópica nas áreas de dunas do bairro de Felipe Camarão, realizou-se observações in loco, sendo acompanhada de registros fotográficos e entrevistas informais com os moradores do local.

\subsection{2 a Etapa: Produção de Informação}

Esta etapa é de extrema relevância, uma vez que, associada à etapa anterior consistirá numa significativa fonte de informações para o pleno alcance dos nossos objetivos com a realização da pesquisa. Para melhor estrutura deste trabalho, foi realizada pesquisa in loco com os moradores, aos órgãos públicos e estabelecimentos prestadores de serviços ou atividades complementares que surgem nos arredores das áreas de dunas.

\section{OS IMPACTOS AMBIENTAIS NAS ÁREAS DE DUNAS NO BAIRRO DE FELIPE CAMARÃO}

O Bairro de Felipe Camarão, a área em estudo, está situado na zona administrativa Oeste da cidade, o qual possui uma área de 663,40 ha, com uma população de 53.537 mil habitantes (NATAL, 2008). Este bairro possui seis conjuntos habitacionais: Felipe Camarão (Promorar), Felipe Camarão II, Felipe Camarão III, Jardim América, Lavadeiras e Vida Nova (I e II), além de nove loteamentos e seis assentamentos precários: Wilma Maia, Barreiros, Lavadeiras, Torre ou Alta Tensão, Fio e Alemão. Em relação à infraestrutura e equipamentos urbanos o bairro é $80 \%$ drenado e pavimentado, possuindo 23 estabelecimentos educacionais, cinco estabelecimentos públicos de saúde, uma praça, duas feiras livres, entre outros (NATAL, 2010).

Umas das características evidente em Felipe Camarão são a presença de habitações precárias. Segundo dados de Secretaria Municipal de Meio Ambiente e Urbanismo, cerca de 7.500 pessoas vivem em assentamentos sem a mínima infraestrutura básica de serviços urbanos e equipamentos. Isso acaba por retratar uma paisagem urbana marcada pelo uso e ocupação das dunas no bairro. Foram registrados, na pesquisa, que todas as dunas, presentes no bairro, sofrem pelo uso e ocupação desordenado.

Consoante a essa realidade, o bairro de Felipe Camarão, de acordo com Natal (2008) possuem três áreas de dunas que envolvem toda a região, sendo constituída por uma duna móvel e duas dunas semifixas. Neste contexto, compreende-se como dunas, os montes de areias móveis formados por grãos de quartzo depositados pela ação constante do vento dominante, o qual remove os grãos do lado da duna mais exposto à sua ação, ou seja, do flanco dorsal ou a barlavento - e os deposita no lado mais protegido - no flanco frontal ou a sotavento. Dependendo do lugar, esse lado é o mais íngreme da duna, com inclinação de 20 a 35 graus (BARBOSA, 2002). Quanto à posição geográfica, as dunas podem ser: dunas marítimas - localizadas na borda dos litorais; dunas continentais - no interior dos continentes. As dunas marítimas, também chamadas litorâneas, podem alcançar grandes alturas, como as landes francesas com cerca de 100 metros 
ou as do nordeste brasileiro. Além disso, as dunas podem ser estacionárias (fixas) ou migratórias (móveis). As dunas fixas tornam-se estáveis por vários fatores, sendo que o principal deles é o desenvolvimento de vegetação; já as dunas móveis apresentam uma maior movimentação dos grãos de areia pelo vento, por não estarem fixadas.
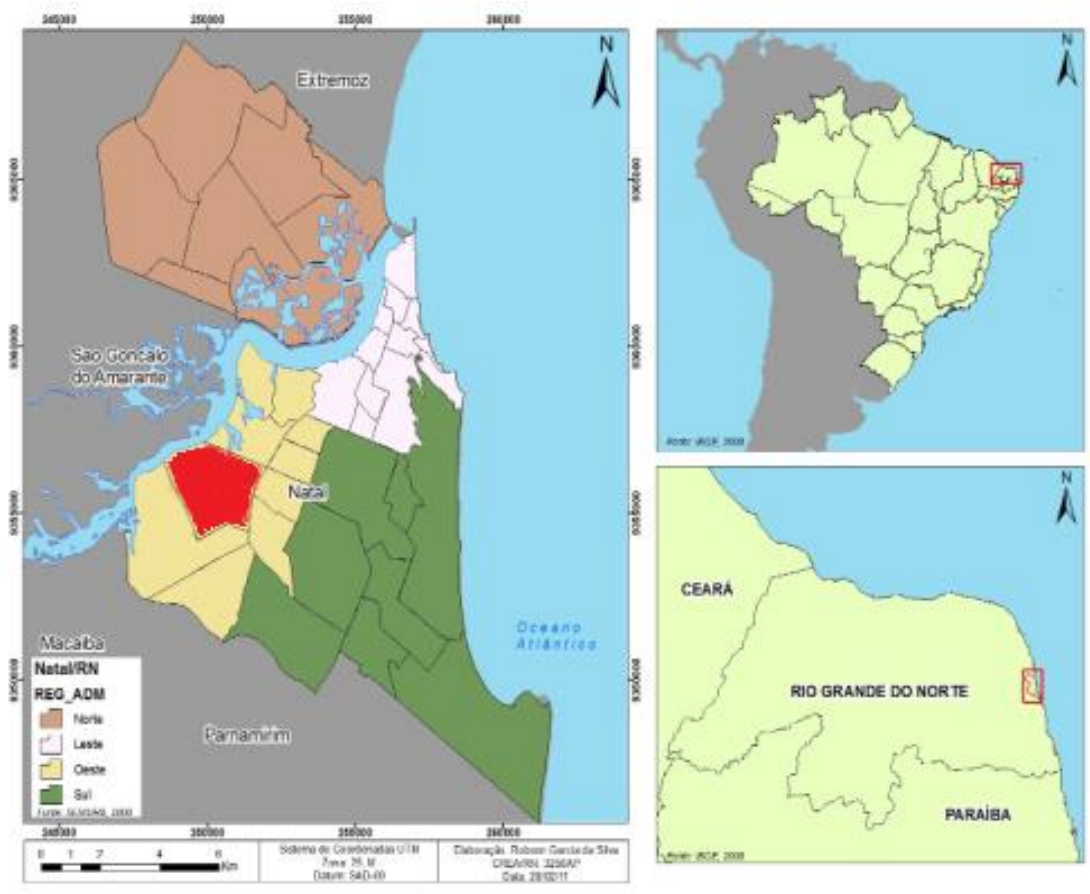

Bairro de Felipe Camarão

Figura 1: Mapa de localização da cidade do Natal e suas zonas administrativas e do Bairro de Felipe Camarão Fonte: Natal (2008), elaborado por Robson Garcia da Silva.

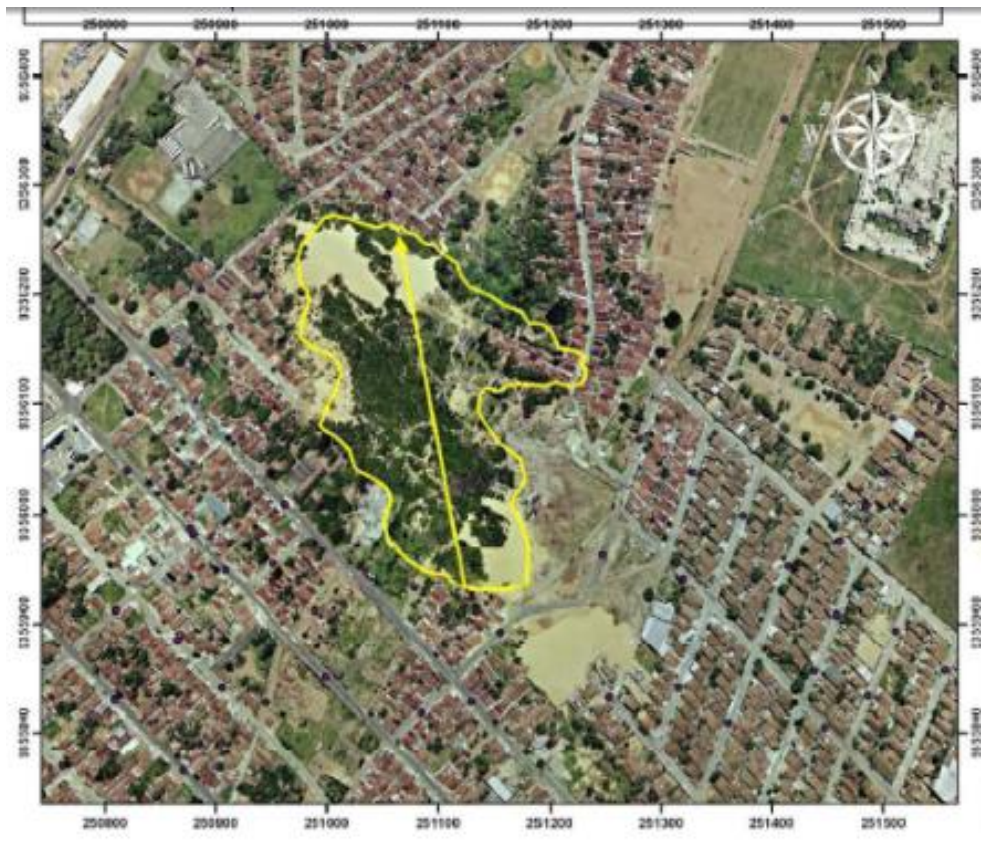

Figura 2: vista área da duna.

Fonte: Natal, 2008.

Em vista disso, a primeira região de dunas observada na pesquisa (figura 02) caracterizase por ser uma duna semifixa. Com uma área de 4. 88hectares e perímetro de 1107 metros 
localiza-se ao norte com a rua Pedrinho Bezerra e Rua São Francisco; ao sul com a rua Córdoba e travessa Santa Clara; ao Leste, com a rua da Fé; já as ruas São José e Mensageiro Jaime, fazem limites a oeste, (Natal, 2008). Nessa região se observa uma ocupação antrópica nos flancos dunares (figura 3), além da mesma servir como depósito de lixo (figura 4) e ser via de acesso dos pedestres para outras ruas. Consequentemente, essas ações desenvolvidas na região têm sido responsáveis por permitir uma instabilidade da feição dunar, fazendo surgir uma área de risco, como o desmatamento e a construção desordenada em seu entorno, como também a proliferação de doenças com o acúmulo de lixo.

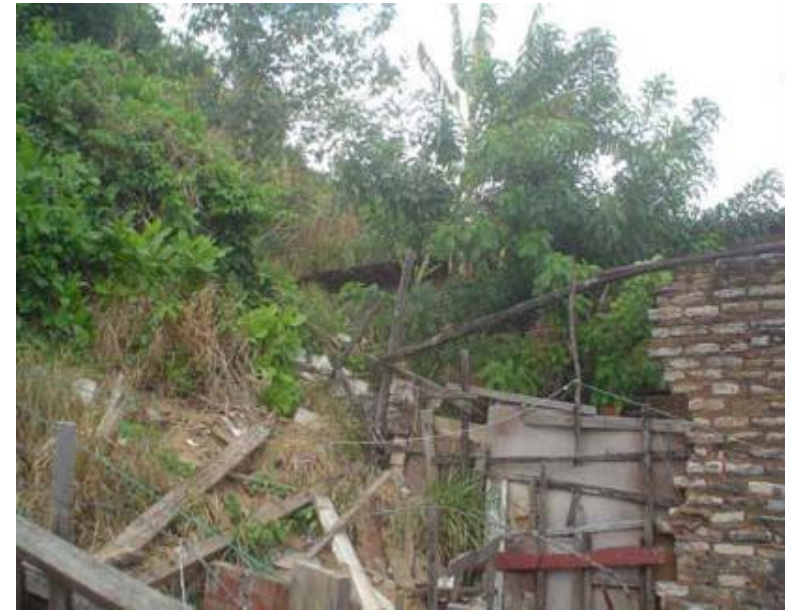

Figura 3: Casa construída próxima à duna. Fonte: Natal, 2008

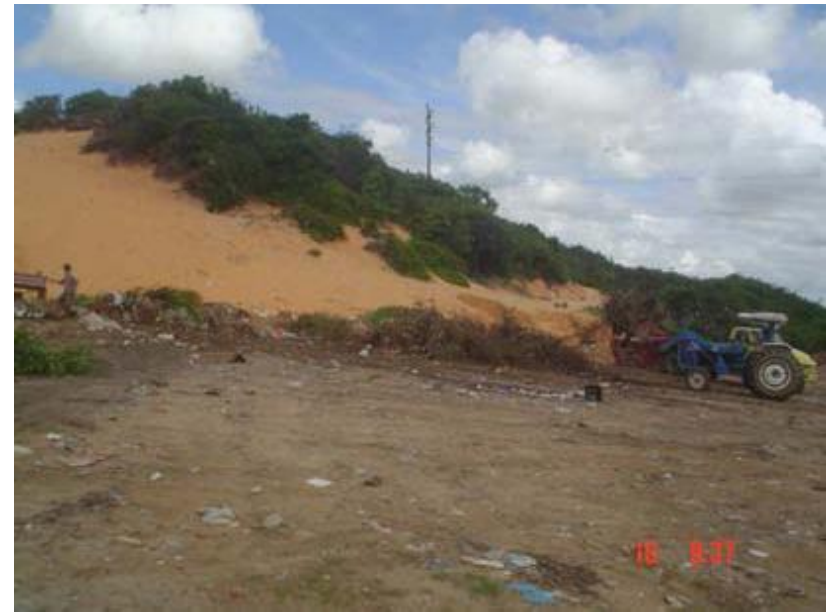

Figura 4: lixo sendo jogado na duna. Fonte: Natal, 2008

A segunda área de duna do nosso estudo (figura 5) apresenta-se com uma área de 0, 73 hectares e perímetro de 376, 48 metros a qual é caracterizada por ser uma duna móvel limita-se ao norte do bairro, fazendo limite com a rua Córdoba/travessa Santa Clara; ao sul, com a rua Managuá; a leste, com rua Mar del Plata e Avenida Brasil; por fim, a oeste com a rua São José (NATAL, 2008).

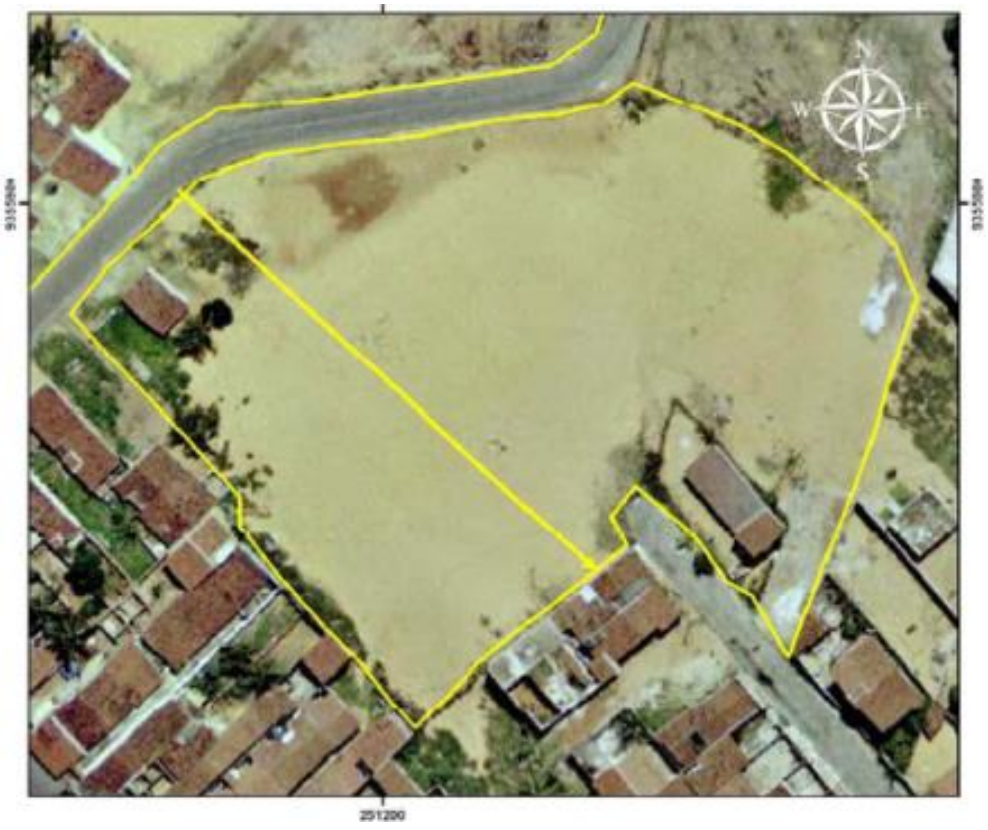

Figura 5: vista área da duna.

Fonte: Natal, 2008 
A duna apresenta em seu entorno uma intensa ocupação antrópica, como se pode observar também na figura 6, com a construção de moradia em seu topo, o qual possui raras porções de vegetação. De acordo com as entrevistas com moradores locais, a mesma sofreu ainda com as retiradas de sedimentos para as construções. Dessa forma, sua feição original vem sendo constantemente descaracterizada.

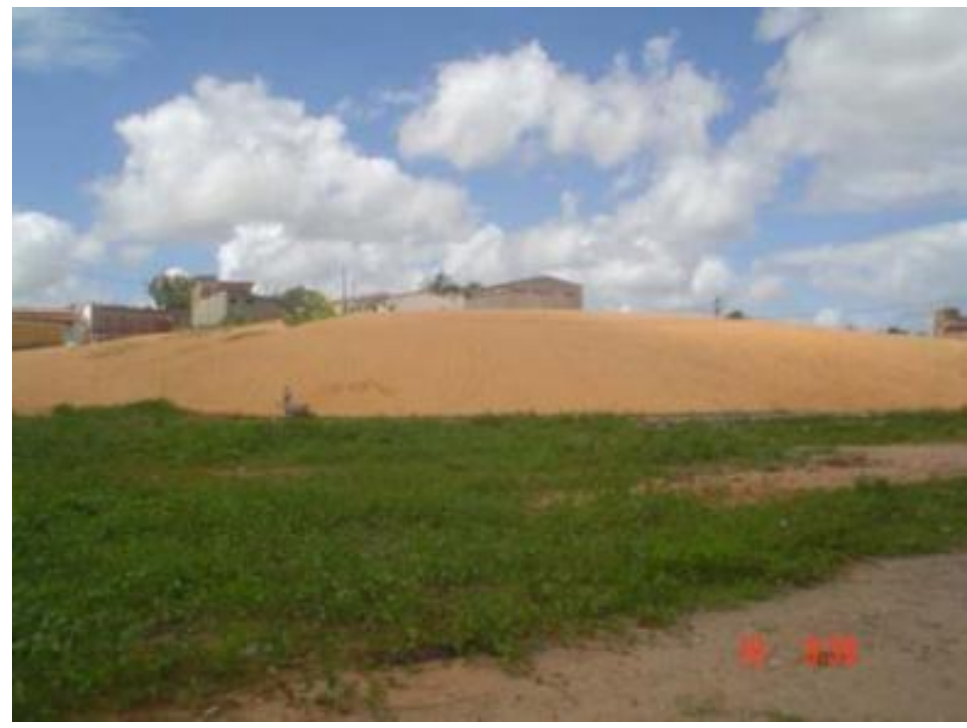

Figura 6: Moradias construídas sobre a duna e vegetação em seu entorno. Fonte: Natal, 2008

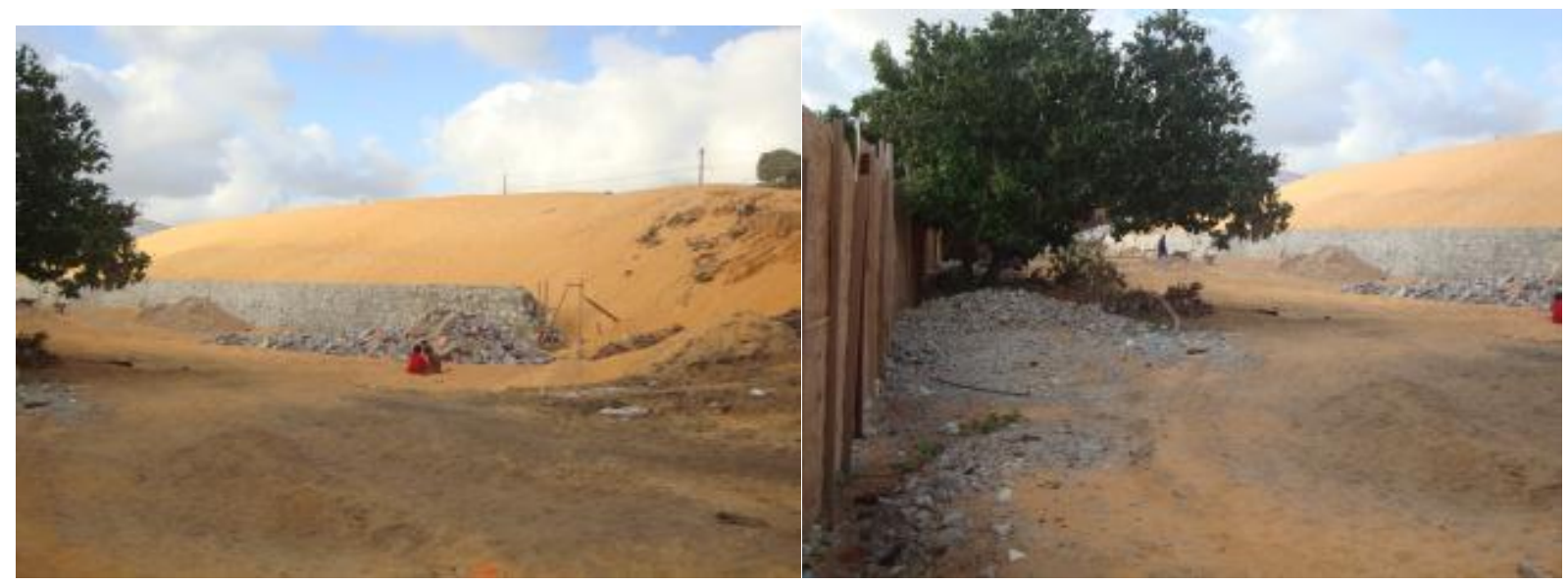

Figura 7: Praça de esporte e cultura construída sobre a duna.

Fonte: A autora, 2013.

Atualmente, a duna está sendo usada para a construção de uma praça de esporte e cultura, como se verifica na figura 7. A obra está sendo promovida pela Prefeitura do Natal, por meio da Secretaria Municipal da Juventude, Esporte, Lazer e Copa do Mundo da FIFA (Secopa). O Equipamento contará com quadra de esportes coberta, pista de skate, Centro de Referência em Assistência Social (CRAS), telecentro, cineteatro, pista de caminhada, biblioteca, canteiro de leitura, equipamentos de ginástica, espaço de cultura, playground, com o custo total de $R \$ 2,2$ milhões de reais.

A terceira área de duna está caracterizada por ser semifixa e situa-se no limite nordeste da ZPA-4, entre a travessa Palmeirinha e a travessa Ferro Cardoso, possuindo uma área de 6,81 
hectares e perímetro de 1491 metros (ver figura 8). Limita-se, ao norte, com a Rua Ferro Cardoso; ao sul, com o final da rua José Vicente/ZPA-04; a leste, com a rua Indomar e a;oeste com o final da rua Rainha do Mar/ZPA-04 (NATAL, 2008).

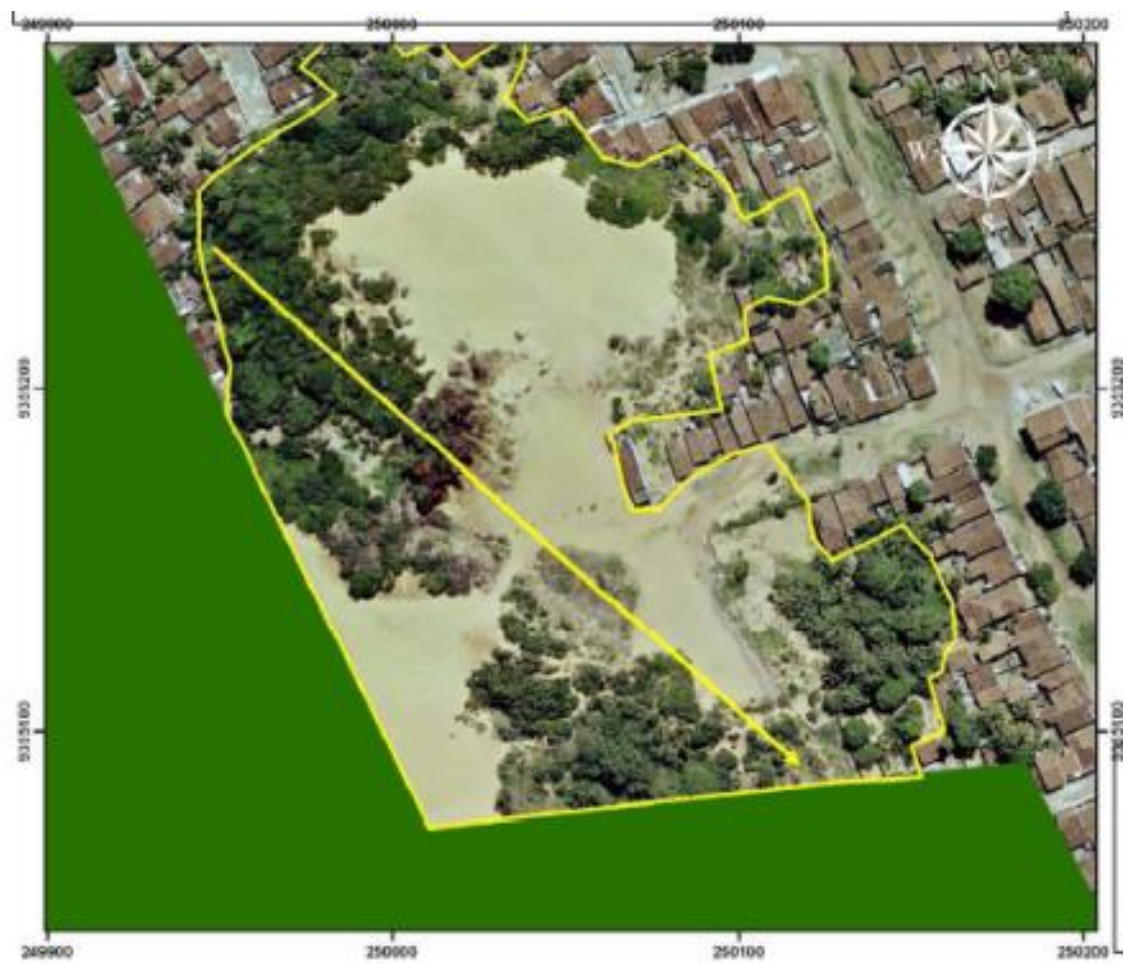

Figura 8: vista aérea da duna.

Fonte: Natal, 2008

Conforme visita in loco e entrevistas com moradores, a duna apresenta um grande perfil topográfico íngreme, gerando uma situação de deslizamento na área e, consequentemente, colocando em risco a vida dos moradores em seu entorno (Figura 10). Além disso, ocorre desmatamento da vegetação para dar acesso à construção de moradias, retirada de áreas para construções e deposição de lixo.

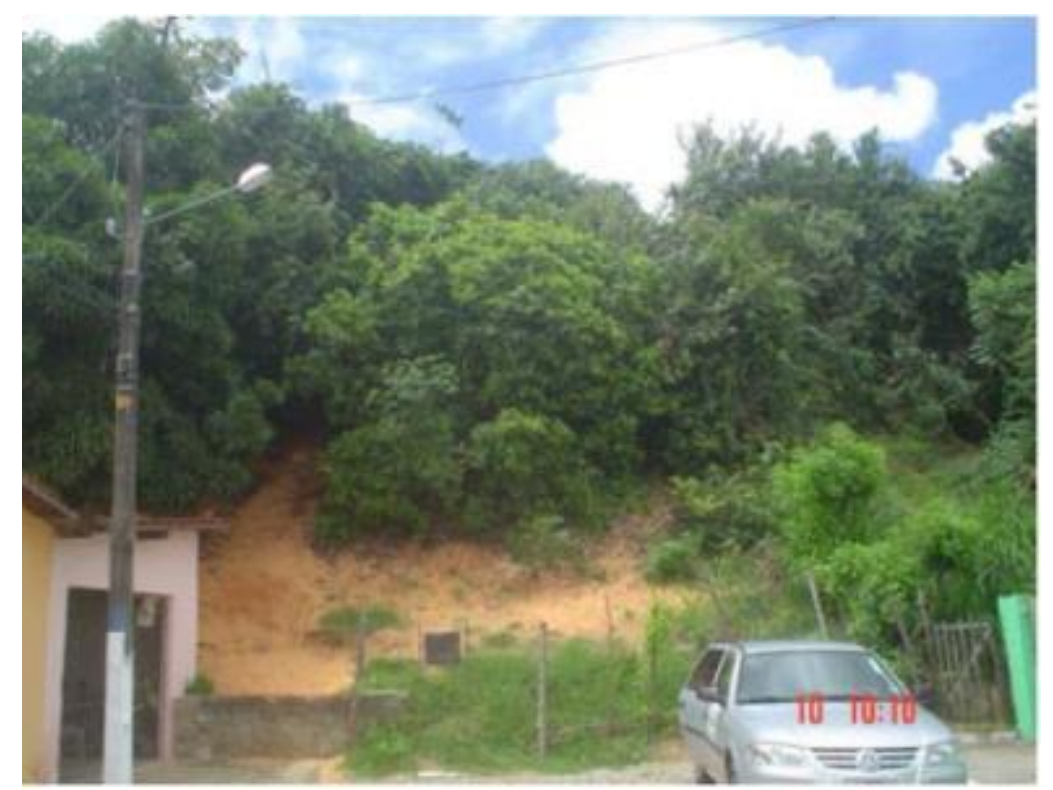

Figura 9: residências construídas em área dunar com risco de deslizamento Fonte: Natal, 2008 
Em suma, sabe-se que as áreas de dunas têm grande importância para a cidade de Natal, pois funcionam como filtradores de águas que percolam e abastecem o lençol freático da cidade, além de trazerem uma melhoria nas condições climáticas locais, beleza na paisagem e até mesmo um potencial turístico em se tratando das dunas costeiras. De acordo com dados da prefeitura do Natal, partes das áreas de dunas do município encontram-se delimitadas em Zonas de Proteção Ambiental - ZPAs. Nessas zonas, são estabelecidas subzonas de uso e ocupação. Essas áreas são dotadas de fragilidade ambiental ou interesse especial. Dentre a legislação pertinente às áreas de dunas no âmbito municipal, temos: LEI MUNICIPAL № 4.100, DE 19 DE JUNHO DE 1992 - CÓDIGO DO MEIO AMBIENTE DO MUNICÍPIO DO NATAL.

Conforme as diretrizes da lei 4.100 no seu Art. 10 discorre o meio ambiente como sendo um patrimônio comum da coletividade, bem de uso comum do povo, e sua proteção é dever do Município e de todas as pessoas e entidades que, para tanto, no uso da propriedade, no manejo dos meios de produção e no exercício de atividades, deverão respeitar as limitações administrativas e demais determinações estabelecidas pelo poder público, com vistas a assegurar um ambiente sadio e ecologicamente equilibrado para as presentes e futuras gerações.

Dessa forma levando em consideração, de acordo com o Art. 55 (da lei 4.100), as dunas são áreas de preservação permanente, e como tal devem ser proibidas quaisquer atividades que ponha em risco a integridade de sua fauna e flora, tais como: circulação de qualquer tipo de veículo, campismo, piquenique, extração de área, depósito de lixo, urbanização ou edificações de qualquer natureza, mesmo desmontáveis, retirada de frutos pendentes, culturas agrícolas, pecuária, inclusive as de médio porte, queimadas e desmatamentos e aterros e assoreamentos.

Entretanto, mesmo respaldada por lei e pela qualidade de vida ambiental que proporciona a população, as dunas sofre pela pressão de ocupação cada vez mais forte por parte da população mais carente da cidade. É evidente que a fragilidade do solo não é empecilho para os que ali se abrigam; mas pelo contrário, é a saída encontrada pelos que vivem sob a margem do capitalismo selvagem e excludente.

\section{CONSIDERAÇÕES FINAIS}

Consoante ao que foi explanado neste trabalho observa-se que as leis que regem a preservação do uso e ocupação das áreas de dunas na cidade do Natal não são cumpridas de forma incisiva, o que leva muitos moradores a usarem essas áreas de forma irregular pondo em risco as suas próprias vidas. Constatamos que as áreas destacadas no bairro de Felipe Camarão vêm sofrendo ao longo dos anos uma degradação por parte da população com a retirada de areia, deposição de resíduos sólidos, construção de moradias, desmatamento da vegetação, abertura de via de acesso e outras interferências.

O número elevado da população, a carência de infraestrutura urbana e serviços básicos, além de construções de assentamentos precários, em locais irregulares (áreas indevidas por parte da população que não pode pagar um imóvel) têm contribuído para que o uso e ocupação das áreas de dunas no bairro de Felipe Camarão se tornem mais constantes.

Desse modo, as áreas de dunas destacadas nesse trabalho vêm sendo constantemente descaracterizadas de sua forma natural, principalmente pela ocupação antrópica e pela má preservação de seu uso. Tendo em vista a importância desse ecossistema 
para a população e zonas naturais de infiltração de água pluvial, muito ainda deve ser feito para que haja uma preservação e conscientização não só por parte da população, mas por parte primordial do poder público local. Cortes e aterros de grandes extensões causam compactação e erosão dos solos. Desse modo, a água não infiltrada flui por galerias e sistemas de drenagem artificiais, carreando partículas do solo que, dimensionados para uma carga de água limite, muitas vezes não conseguem escoar o excedente, podendo ocasionar inundação em períodos de intensa precipitação pluviométrica.

Torna-se imprescindível a proteção dos remanescentes de dunas aqui identificados, tanto pelo aspecto da conservação da biodiversidade, quanto pela importância paisagística e para a recarga dos lençóis subterrâneos, além do fato do solo dunar ser reconhecidamente impróprio para abrigar habitações ou outras construções devido aos riscos de deslizamento causados pela instabilidade desse tipo de solo.

\section{REFERÊNCIAS BIBLIOGRÁFICAS}

1. ABRAMO, Pedro. A Cidade COM-FUSA. A mão inoxidável do mercado e a produção da estrutura urbana nas grandes metrópoles latino-americanas. Revista Brasileira de Estudos Urbanos e Regionais, v.9, n.2, 25-54, nov. 2007.

2. ARAÚJO, Regina Célia. Manual do Candidato de Geografia. Brasília: FUNAG, 2007.

3. BARBOSA, L. M. 2002. Dunas ao sabor dos ventos. Ciência Hoje das Crianças. In: http://cienciahoje.uol.com.br/view/2057. Acesso em 09/01/2013.

4. CARLOS, Ana Fani Alessandri. A (Re)produção do espaço urbano. São Paulo: Editora da Universidade de São Paulo, 1994.

5. CÓdIGO DO MEIO AMBIENTE - LEI No 4.100/92. LEI №. 4.100, DE 19 DE JUNHO DE 1992. Disponível em: <http://www.natal.rn.gov.br/arsban/paginas/File/legislacao/LeiMunicipal 4100-1992.pdf.> Acesso em: 20/09/2012.

6. CONSELHO NACIONAL DO MEIO AMBIENTE. RESOLUÇÃO CONAMA № 001, de 23 de janeiro de 1986. Publicado no D. O. U de 17 /2/86. Disponível em: < http://www.mma.gov.br /port/co nama/res/res86/res0186.html> Acesso em: 20/09/2012

7. CORRÊA, Roberto Lobato. Espaço Urbano. São Paulo: Ática, 1995.

8. ___ Trajetórias geográficas. Rio de Janeiro: Bertand Brasil, 2001.

9. FERNANDES, Edésio. Programas de regularização fundiária em áreas urbanas: comentários e lições. Oculum ensaios, Campinas, n.6, p. 47-57, jul/dez, 2006.

10. INSTITUTO BRASILEIRO DE GEOGRAFIA E ESTATÍSTICA. Dados básicos da cidade de Natal, 2010. Disponível em: <http://www.ibge.gov.br/cidades. Acesso em 10/12/2011.

11. MARICATO, Ermínia. As idéias fora do lugar e o lugar fora das idéias. In: MARICATO, E. et. Al. A cidade do pensamento único: desmanchando consensos. Petrópolis, Vozes, 2000.

12. MOTA, Suetônio. Urbanização e Meio Ambiente. Rio de Janeiro: ABES, 2003.

13. NATAL, Prefeitura Municipal de. Secretaria de Meio Ambiente e Urbanismo. Anuário de Natal. 2010. Disponível em: < http://www. natal.rn.gov.br. Acesso em: 10/01/2013.

14. Conheça melhor seu bairro. 2009. Disponível em: < http://www. natal.rn.gov.br. 
Acesso em: 10/12/2012

15. . Natal, Ontem e Hoje. 2006. Disponível em: <http://www. natal.rn.gov.br. Acesso em: $11 / 01 / 2013$.

16. _. Dunas: Relatório e altas do mapeamento e caracterização dos remanescentes de dunas no município de Natal. 2008. Disponível em: <http://www. natal.rn.gov.br. Acesso em: $30 / 10 / 2012$.

17. NASCIMENTO. Gerson Gomes do. Shoppings-Centers: elementos de (re)produção na Zona Sul de Natal-RN. 2003. 178f. Dissertação (Mestrado em Geografia) UFRN, Programa de pósgraduação em geografia, Natal, 2003.

18. VALENÇA, Márcio Moraes. Habitação: notas sobre a natureza de uma mercadoria peculiar. Caderno metrópole, n.9, p. 165-171, 2003. Disponível em http://www.cadernosmetropole .net/pt/component/content/article/50-44

19. VICTORINO, Celia Jurema Aito. Canibais da Natureza: educação ambiental, limites e qualidades de vida. Petrópolis. Rio de Janeiro: Vozes, 2000. 